\section{(6) OPEN ACCESS}

\title{
Parental enhancement and symmetry of power in the parent-child relationship
}

\author{
Anca Gheaus
}

Correspondence to Dr Anca Gheaus, Department of Law, Universitat Pompeu Fabra, C/ Ramon Trias Fargas 25-27 08005 Barcelona, Spain; agheaus@gmail.com

Received 10 December 2016 Accepted 25 April 2016

\begin{abstract}
Many instances of parental enhancement are objectionable on egalitarian grounds because they unnecessarily amplify one kind of asymmetry of power between parents and children. Because children have full moral status, we ought to seek egalitarian relationships with them. Such relationships are compatible with asymmetries of power only to the extent to which the asymmetry is necessary for (1) advancing the child's level of advantage up to what justice requires or (2) instilling in the child morally required features. This is a ground to oppose parental enhancements whose purpose is either to merely satisfy parents' preferences or to confer on the child advantages above and beyond what the child is owed by justice.
\end{abstract}

It has always been like that: as a birth parent you could not choose your child but had to put up with whatever chance had dealt you. And, I shall argue, there is something desirable about this fact. Children, too, are unable to choose their parents, and this will not change. By contrast, with the help of technology, parents are able to increasingly determine features of their future biological children and, in this way, gain some control over whom they parent. I call this 'parental genetic shaping' to distinguish it from other kinds of shaping that parents do-for instance, through education or through the choice of various conditions in which their children grow up. My focus here is on one type of parental shaping, namely parental choices to use technology to determine, or increase the likelihood of, particular features of their already existing embryos. Call this 'parental enhancement' to distinguish it from parental decisions to implant embryos based on their (higher likelihood to display) particular features. My argument concerning parental enhancement applies to embryo choice in a similar way, ${ }^{\mathrm{i}}$ but more argument would be needed to show how, because an embryo choice is also a case of deciding over the very existence of a future individual.

This paper does not go as far as concluding that every kind of parental enhancement is, all things considered, morally undesirable-the matter is too complex to settle in a short piece. ${ }^{\mathrm{ii}}$
${ }^{\mathrm{i}}$ As I argue in Gheaus (Gheaus A. "Parental genetic shaping and parental environmental shaping", unpublished manuscript).

${ }^{\mathrm{ii}}$ For discussion of various normative aspects of parental shaping, see refs. ${ }^{1-5}$
Even less is the paper about the legal status of parental genetic shaping. Rather, I have the more modest aim of explaining why an egalitarian must find some instances of parental enhancement unjust. My focus is on parental enhancements that are not necessary to ensure that the child has what she is owed by justice and which do not concern morally mandatory features. Such enhancements amplify the asymmetry of power between parents and children without good reason. Unjust instances of parental enhancement are, I assume, all-things-considered morally impermissible.

The argument proceeds from premises (P1-P6) to intermediary conclusions $(\mathrm{C} 1-\mathrm{C} 3)$ to the general conclusion (C4). In several steps of the argument, P1 functions as a major premise. In a nutshell, I argue that:

P1. Children have the same moral status as adults.

C1. Therefore, we ought to seek childrearing arrangements that embody egalitarian relationships with children.

P2. Proviso: egalitarian relationships with children are compatible with asymmetries of power only to the extent to which the asymmetry is necessary for (1) advancing the child's level of advantage up to what justice requires or (2) instilling in the child morally required features.

P3. Voluntariness is one aspect of the power dimension of a relationship. The voluntariness of a relationship is a function of the voluntariness of entering it and the voluntariness of exiting it.

C2. Therefore, egalitarian relationships between parents and children ought to display as much symmetry of entry and exit as possible given the proviso. P4. Parents unavoidably enjoy more voluntariness with respect to entering the parent-child relationship than children.

P5. The more choice a person has to determine the identity of her partner in a relationship, the better positioned that person is to enter that relationship voluntarily.

P6. Parental enhancement gives prospective parents some power to determine the identity of their future children.

C3. Therefore, parental enhancement introduces inequality of voluntariness in the relationship between parents and children and is a prima facie threat to the ideal of an egalitarian relationship between parents and children.

C4. Therefore, parental enhancement can be justified only if it is necessary for the child to reach the level of advantage that she is owed by justice, or if it is aimed at morally mandatory features. 
The rest of the paper defends the premises and explains how the conclusions follow. Some premises are more obvious than others.

A first example is the first, major premise P1: that children have full moral status, that is the same moral status as adults. This premise, which I assume is generally undisputed, states the basic moral equality between children and adults: Its truth is by no means universally accepted; historically, some philosophers believed that children and adults do not enjoy basic moral equality-thus justifying ownership rights of adults over children. ${ }^{\text {iii }}$ And it is unclear whether contemporary libertarians can acknowledge children's full moral status. ${ }^{7}$ In spite of some historical and possibly contemporary opposition, I assume that the first premise is true. This assumption implies that both kinds of individuals-children and adults-are being owed duties of justice and are rights holders. Believing this is compatible with the possibility that children and adults hold rights on different bases. Throughout this paper, I assume that children's rights protect their interests, rather than their choices-but, importantly, one of children's morally weighty interest is to be allowed to make choices that are compatible with their level of intellectual and emotional development. ${ }^{8} 9$ Adults' rights, by contrast, can protect both. ${ }^{10}$ If children and adults have the same moral status, then children have a moral right to have egalitarian relationships with adults, including their own parents. Therefore, (C1) we ought to seek childrearing arrangements that embody egalitarian relationships with children.

To determine what it means for a relationship with children to count as egalitarian, I will now defend P2, containing the following proviso: Egalitarian relationships with children are compatible with asymmetries of power only to the extent to which the asymmetry is necessary for (1) advancing the child's level of advantage up to what justice requires or (2) instilling in the child morally mandatory features. Since the second clause (2) is obvious, I will concentrate on defending the first.

Moral equality between children and adults does not mean that both parties have the same rights, nor do egalitarian relationships between children and adults require perfect symmetry of power. Like most, ${ }^{\text {iv }}$ I assume that children do not have the moral authority to make the same choices as adults although, as they grow up, the scope of their authoritative choices expands, and they may have moral authority over more choices than usually assumed by the legal status quo. Children have important, rights-generating interests that they cannot protect by themselves, especially when very young. Therefore, they are entitled to adult action aimed at protecting these interests. For this reason, adults have a duty to promote children's well-being up to a certain level, and some adults-most obviously, parentshave the right to make choices on children's behalf, to the extent to which these choices are necessary to promote the wellbeing owed to children up to a certain level and children's moral development. Thus, some asymmetry of power between children and their parents is legitimate and required by, rather than undermining, egalitarian. Children, for instance, have a powerful, rights-generating interest to stay alive and, as long as they do not have the authority to judge how they can best ensure that their interest is met, their parents are entitled to make, for instance, medical decisions on their behalf. Similarly, children have a powerful, rights-generating interest to develop into functioning and autonomous adults; for this reason, their

\footnotetext{
${ }^{\text {iii Most famously, Aristotle. }}{ }^{6}$

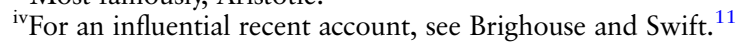

parents have a right to teach them, for instance, the ways of peaceful social interaction (and demand them to comply). By contrast, children do not have the authority to either make medical decisions on behalf of their parents or to discipline them.

The crucial question, then, is how to identify the threshold that determines legitimate exercise of parental power-that is, the exercise of parental power that is compatible with egalitarian relationships between parents and children. Existing legislations allow parents to exercise their power over children to confer on to them unlimited advantage as long as the parent is in otherwise rightful possession of the necessary means. For instance, parents are allowed to enrol their children in elite, expensive private boarding schools, whether or not the child is willing. More generally, parents are legally permitted to exercise their power over children to decide about virtually every aspect of the child's life as long as they respect certain constraints concerning the child's safety and well-being — that is, as long as they do not abuse or neglect their children and, in most countries, as long as they comply with certain demands concerning medical checks and children's compulsory education. For instance, parents may educate their children in their own religion and forbid them to develop close relationships with atheists or with members of other religions.

But neither the permission to use parental power to advance parents' own interests, nor the permission to use it to confer any amount of benefit on to the child, can be legitimate. According to many philosophers, and possibly to common sense morality, existing legal constraints on the use of parental power fall short of the moral demands of adequate parenting. Here, I follow a number of liberal egalitarian theories of justice in childrearing, according to which legitimate exercise of parental power over children is indeed very restricted by comparison to what tradition and common sense morality allows. ${ }^{11}{ }^{12}$ Liberals who acknowledge the equal moral status of children and adults must deem illegitimate uses of parental power that set back one's child interest and also uses of parental power that are not necessary to advance a child's well-being. Take, for instance, a parent's decision that her child undergoes very low-risk hormonal treatment to ensure the child will grow up to a certain height because shethe parent-would like to have a tall child. Assume this decision is unlikely to contribute to the child's well-being: suppose that, after therapy, the child would become a successful basketball player and that, in the absence of the therapy, she would become an equally successful runner. Yet, the parent strongly prefers a basketball career for her child, and this is the reason to go for hormonal therapy. In this case, the parental exercise of power is illegitimate. Egalitarians believe that children are entitled to their fair share of resources, or (opportunities for) welfare, or to a certain number of capabilities. If they also think that individuals are proper agents of justice, they will be committed to the view that uses of parental power is illegitimate if it is aimed at giving the child more than her fair share. One of the usual illustrations of illegitimate use of parental power involves parents enrolling their children into an elite, expensive private school to give them competitive advantage, especially if adequate public education is available. ${ }^{11} 13 \mathrm{~A}$ common complaint against the parent who chooses hormonal treatment for her child and against the parent who puts her child into a private school can be expressed as an objection to illegitimate use of parental power. Both parental decisions amplify the asymmetry of power between parents and children without, in the first case, necessarily contributing to the well-being of the child and, in the second case, without them being necessary to 
ensure that the child will reach the level of well-being required by justice.

All the examples I used so far concern one aspect of the power relationship between parents and children: parents' asymmetrical authority to make decisions concerning children's lives. Another element that is relevant to the power aspect of a human relationship concerns its voluntariness-that is, whether the relationship has been entered freely and whether the parties to the relationship are free to dissolve it (P3). If, for instance, two individuals are in a relationship which one of them can exit at low cost and the other one at high cost, then the first person has more power over the second person: the first person can use her better exit options to set the conditions of the relationship. This seems objectionable-as republican political philosophers insist ${ }^{14}$ - even when the higher level of power conferred by better exit options is not in fact used to set back the options of the weaker party. The egalitarian intuition here is that moral equals should not have unequal exit options because, absent special justification, this inequality seems inconsistent with the two parties' equal moral status.

The same can be said about enjoying the same level of voluntariness with respect to entering a relationship between equals. The real importance lies with parties having the same level of choice, rather than with the parties always making autonomous choices about entering the relationship. Think for instance, about the relationship between natural siblings: neither has a choice of whether or not to enter a relationship with the other sibling, yet, since they are symmetrically situated in this respect, sibling relationships seem as such unobjectionable to egalitarians. By contrast, consider the following imaginary case: Alexis and Eirian are partners in a marriage that is perfectly egalitarian as far as spouses' rights and duties are concerned. However, only one of them, Eirian, has voluntarily decided to enter the marriage, while the decision that Alexis gets married was made by Alexis' family. Unlike the siblings' case perhaps, it would be objectionable if both Eirian and Alexis were married off by their families; but the case just described is particularly objectionable on egalitarian grounds because the asymmetry of choice at entry seems, again, inconsistent with the two spouses' equal moral status. Other things equal, an egalitarian relationship will display the same level of voluntariness with respect to entry and exit for all parties.

But between parents and children things are not equal, as the above discussion shows. Children have morally weighty interests, some of which are rights generating and for the fulfilment of which they need to rely on some adults. This justifies parents' rights to decide for their children and also unequal exit options for children and parents from their relationship. Most legislations do not allow children to 'divorce' their parents at will; as long as parents are not abusive or neglectful, a child can usually exit the relationship with her parent only at pain of becoming homeless and an outlaw. It is debatable whether we ought to relax children's exit options from their relationship with their parents, ${ }^{\mathrm{V}}$ but, in any case, we should acknowledge that in some situations it is in the child's best interest to face very high costs of exiting the relationship. Parents, too, are-for good reasonunable to dissolve the relationship with their children lightly. ${ }^{15}$ But, the costs faced by parents are not equally high: it is technically easy for new birth parents to put their children up for adoption and it is plausible that we ought to allow parents who feel they cannot parent well (anymore) to step out of their parental role. Therefore, strictly equal levels of voluntariness with respect to exit are not an ideal in the parent-child relationship. Rather, (C2) egalitarian relationships between parents and children ought to display as much symmetry of voluntariness on both sides as possible, given that proviso is satisfied.

The relationship between parents and children is asymmetrically voluntary with respect to exit and it is also-in part unavoidably-asymmetrically voluntary with respect to entry. We do not choose to be born, nor could we conceivably make such a choice. Because we come into existence as non-agents, it is not possible to give a prospective child the option to enter the relationship with her future parents in a voluntary way. Our parents, however, have some degree of control with respect to entering parenthood-and, in places where adequate contraception and education are available, becoming a parent is a voluntary choice. It is likely that the great harm represented by unwanted pregnancies and childrearing responsibilities means that this asymmetry of choice between parents and children is all-things-considered justified. Whether or not this is so, it is clear that unlike the asymmetry of exit, the asymmetry of entry is unavoidable. Therefore, (P4) parents unavoidably enjoy more voluntariness with respect to entering the parent-child relationship than children.

Yet, how voluntary is entry into a relationship which is defined by pre-established rights and duties turns on two factors. One is whether or not a person agrees to enter a type of relationship (are Alexis and Eirian willing to get married at all?). The other is whether or not the person has a choice with respect to the particular individual with whom she is entering the relationship (are Alexis and Eirian willing to get married to each other rather than to different eligible partners?). This means that (P5) the more choice a person has to determine the identity of her partner in a relationship, the better positioned that person is to enter that relationship voluntarily.

Traditionally, parents and children have been equals with respect to how much choice they had in the second respect: none. However, (P6) parental enhancement gives prospective parents some power to determine the identity of their future children.

The next question is whether increased parental choice with respect to some features of one's future child poses a prima facie challenge to the egalitarian nature of the parent-child relationship. Children cannot be given a similar-or, indeed, anypower to intentionally influence the characteristics of their parents-to-be. It may be the case that embryos effect some changes on their gestational mother, in utero ${ }^{\mathrm{vi}}$ - but these can only be unintentional influences. Now remember Alexis and Eirian, and imagine one variation: that they live in a society where all marriages are arranged by the family of the spouses. Imagine, further, that neither Eirian nor Alexis has a choice of whether or not to marry but Eirian is told about a few differences between the potential spouses and allowed to decide which to marry based on this knowledge. Alexis has no similar choice. If Eirian makes use of this limited available choice, the egalitarian nature of the future relationship between Eirian and Alexis is, in one respect, compromised. Yet, you may object that embryos and newborns are unlike Alexis and Eirian in one important respect: embryos or newborns do not have any choice and they are not capable of any choice-let alone 
morally authoritative choice. For this reason, you may think that the asymmetry of choice in question is entirely irrelevant to how egalitarian the future parent-child relationship will be. My rejoinder is that, although embryos and newborns cannot choose, children can, staring at a very young age. In general and ideally, a child will be parented by the same person continuously; therefore, the same, entirely unchosen, person will be the parent even when the child reaches an age when she can make some morally authoritative choices. At the very latest at that moment, it will become relevant that the child and the parent are part of a relationship in which only one party had some choice over the identity of the other. But, more likely, the fact that only one party had some choice is morally relevant from the very beginning, since part of the parental duty is to do what it takes to bring up an autonomous individual: the child should one day be able to look back on her life and understand that she has always been part of a relationship shaped by avoidable asymmetry of power. ${ }^{\text {vii }}$ Therefore, parental enhancement introduces inequality of voluntariness in the relationship between parents and children and is a prima facie threat to the ideal of an egalitarian relationship between parents and children (C3).

Whether this prima facie threat actually undermines the egalitarian nature of the relationship will depend on the kind of enhancement in question and the parents' motivation for enhancing. A decision to determine certain bodily enhancements-like height or eye colour-meant to merely satisfy parental preferences do undermine the egalitarian nature of the relationship, since parental power over the child is not permissibly used merely to advance the parents' interests. The same is true about enhancements that parents choose to give their child advantages above and beyond what is required by justice, for instance, a superior IQ.

It is not my aim here to defend a particular conception of what we are owed by justice, neither in terms of the right principle (like equality, sufficiency or priority) nor in terms of the right metric (like opportunities for welfare, resources or capabilities). Even less can I specify with any precision which particular enhancements are necessary to ensure one's future child will not fall below the level of advantage that she is owed by justice. This will depend both on the theoretical choices of principle and metric mentioned above and on empirical matters. But some cases seem unproblematic: certain medical enhancements - for instance, against high likelihood of future disease or disability-are likely to be necessary to ensure the child will reach the level of advantage required by justice. This is because we quite trivially believe that justice requires us to eliminate disease and disability when we can do this for all affected. Also, the recently much discussed moral enhancements ${ }^{17}$ may be

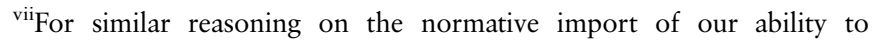
evaluate our early relationship with our parents, see Clayton (ref, 12 pp. 106-107).
}

protected by the proviso when they concern features that are morally required. Note, however, that when an embryo requires treatment against future disadvantage, or the enhancement of morally required features, it is better for the enhancement to be a matter of public, state sponsored decision rather than be left to the discretion of parents. ${ }^{18}$ Yet, absent such policies, parental decision to enhance for this kind of features is compatible with the egalitarian nature of the parent-child relationship. Therefore, (C4) parental enhancement can be justified only if it is necessary for the child to reach the level of advantage that she is owed by justice, or if it is aimed at morally mandatory features.

Competing interests None declared.

Provenance and peer review Commissioned; externally peer reviewed.

Open Access This is an Open Access article distributed in accordance with the Creative Commons Attribution Non Commercial (CC BY-NC 4.0) license, which permits others to distribute, remix, adapt, build upon this work non-commercially, and license their derivative works on different terms, provided the original work is properly cited and the use is non-commercial. See: http://creativecommons.org/ licenses/by-nc/4.0/

\section{REFERENCES}

1 Buchanan A, Brock D, Daniels N, et al. From chance to choice. Genetics and justice. Cambridge: Cambridge University Press, 2000.

2 Savulescu J. Procreative beneficence: why we should select the best children. Bioethics 2001;15:413-26.

3 Agar N. Liberal eugenics: in defence of human enhancement. Oxford: Blackwell, 2004.

4 Harris J. Enhancing evolution. The ethical case for making better people. Princeton University Press, 2007.

5 Buchanan A. Beyond humanity? The ethics of biomedical enhancement. Oxford University Press, 2011.

6 Aristotle. Nicomachean ethics. In: Barnes J, ed. The complete works of Aristotle. Princeton University Press, 1984, 5. 6. 1134b.

7 Lipson M, Vallentyne P. Libertarianism, autonomy, and children. Public Aff Q 1991;5:333-52

8 Brennan S, Noggle R. The moral status of children: children's rights, parents' rights, and family justice. Soc Theory Pract 1997;23:1-26.

9 Brighouse H. What rights (if any) do children have. In: Archard D, Macleod C, eds. The moral and political status of children. Oxford: Oxford University Press, 2002:31-52.

10 Vallentyne P. The rights and duties of childrearing. William and Mary Bill of Rights Journal 2003;11:991-1010.

11 Brighouse H, Swift A. Family values. The ethics of parent-child relationships. Princeton University Press, 2014.

12 Clayton M. Justice and legitimacy in upbringing. Oxford: Oxford University Press, 2006.

13 Swift A. How not to be a hypocrite. School choice for the morally perplexed parent. Routledge, 2003.

14 Lovett F. Republicanism. Stanford Encyclopedia of Philosophy. 2014. http://plato. stanford.edu/entries/republicanism/

15 Alstott A. No exit: what parents owe their children and what society owes parents. Oxford University Press, 2004.

16 Gheaus A. Arguments for Nonparental Care for Children. Soci Theory Pract 2011;37:483-509.

17 Persson I, Savulescu J. Unfit for the future the need for moral enhancement. Oxford University Press, 2012.

18 Fowler T. In defence of state directed enhancement. J App/ Philos 2014. 